\title{
Transmission of family health information within families
}

\author{
Patricia Newcomb, Barbara Raudonis, Diane Snow, Denise Cauble
}

College of Nursing, University of Texas at Arlington, Arlington, USA

Email: pnewcomb@uta.edu

Received 20 October 2011; revised 16 December 2011; accepted 18 January 2012

\begin{abstract}
Background and Aims: A comprehensive family health history still offers the best data for calculating risk of most complex diseases, but lack of informant accuracy hinders its use. Young adults transitioning from the parental home to more independent university life may be poor historians. The purpose of this study was to describe the quality of family health information acquired by young university students and to characterize the process by which they learn family health facts. Methods: Thematic content analysis was applied to interviews with undergraduate students enrolled in diverse classes across disciplines at a public US university. Results: Two processes, hanging around and trickling down, described the ways young adults learned family health information. The majority of respondents described both empowerment and a sense of vulnerability that resulted from having their family health information. Conclusions: Family health history provided by young adult students is characterized by inaccuracies related to lack of information and misunderstanding of information that is available. Young students are typically transitioning from the care of local primary care physicians into relationships with new healthcare providers, and are interested in family health history. Thus, this transition is an opportunity for nurses to construct an organized family health history with them.
\end{abstract}

Keywords: Family Health History; Young Adult; Family Communication; Qualitative Research

\section{INTRODUCTION}

Prediction of disease risk is a major public health concern, and accessible tools for risk prediction are critical for population health. The family health history (FHH) is an inexpensive and potentially powerful genomic tool that is readily accessible to all clinicians, but may be under-exploited.

FHH is a highly valued means for translating genome-based knowledge into disease prevention, but little is known about the best ways to obtain FHH or how ac- curacy is affected by factors such as life stage [1]. The United States Centers for Disease Control and Prevention (CDC) recognizes the value of $\mathrm{FHH}$ for identifying shared genes, behaviors, and environments that put individual health at risk [2] and has publicly encouraged the systematic collection and use of FHH information. Clinicians may use the FHH as a decision aid in making diagnoses, as a tool for planning screening and monitoring, and as a patient or family educational device. In spite of its utility, the traditional FHH is underused as a result of multiple barriers to data collection, including lack of time in practice situations [3].

Transferring family health information from patient to clinician is only part of the challenge. The accuracy and completeness of the information determines how useful it is, but the nature of health information sharing among family members is unclear. The purposes of this study were to describe the quality of family health information acquired by healthy young adults who are in the process of transitioning from living with family to living independently as university students and to explore the process of health information sharing. Understanding how young adults obtain facts about family health will help clinicians assist this generally healthy population with documentation important for predicting disease risk.

\section{BACKGROUND}

\subsection{Family Stories}

Transmission of family history creates a record of stories that demonstrate the significance of family members within the group. This transmission is typically oral. It may be misunderstood by others or lost by failure to share the information. Messages regarding values, beliefs, behaviors, and rituals are exchanged, assuring adequate growth and development of the family system. Family stories provide a mechanism for intergenerational connectivity across the lifespan, emphasizing genealogical continuity, and sustaining family coherence. Mothers are thought to transmit family history most often. Mothers have been shown to be strong family gatekeepers, determining not only care and feeding practices for children, but also access to children by other family members, 
including fathers [4-6].

In many cultures grandmothers are considered bearers of family history and tradition; grandfathers educate through life experience and mentoring [7-10]. By fulfilling these roles, older adults meet the developmental need of generativity [11]. Additionally, these roles allow older adults to retain a valued and central position in the family, experience re-involvement with significant events in their past, and derive pleasure from relationships with decreased responsibility [12-15]. Older adults may be the carriers of FHH information in Western society, but their current role in transmitting that knowledge is unknown.

A substantial body of knowledge exists regarding intra-family communication in general, but literature relevant to our research question is typical old. A search of professional databases, including PubMed, CINAHL, and Academic Search Premier, failed to reveal any research directly addressing the intergenerational transfer of family health information among families without known genetic disorders. Literature about behaviors involved in obtaining FHH is focused primarily on individuals affected with or possessing known risk factors for genetic disorders or cancer. This leaves a substantial gap in knowledge regarding less exceptional groups.

\subsection{Conceptual Framework}

Decisions guiding methodological choices in this study are rooted within social constructivism [16,17]. Within this paradigm the FHH constitutes a reality constructed by a group of individuals by means of interaction with each other. Each individual constructs the meaning of the FHH through reflection on past experiences. It is unlikely that each family member will recount an identical FHH or that the FHH will have the same meaning for each member of a family. A qualitative approach has the greatest opportunity to deliver an interpretable description of a socially constructed process that has not been previously studied. This information can generate hypotheses for later testing and can be used to design interventions that assist families to share FHH data with healthcare providers.

\section{METHODS}

Thematic content analysis of transcribed interviews was conducted in a constant comparison approach based on grounded theory methods originally described by Glaser and Straus [18]. The grounded theory approach involves a process of constantly comparing evidence from participants to generate conceptual categories. Properties of conceptual categories are identified resulting in rich descriptions of social processes that can used for various purposes, including theory generation, empirical generalization, or verification of theory. The evidence in this study consists of interviews with young university students, which were compared to each other repeatedly during the interview phase of the study. Conceptual categories were generated from this evidence, properties of the categories were identified, and empirical generalizations were proposed.

\subsection{Sample}

The sample consisted of 18 resident undergraduate students, aged 18 - 24 years enrolled in classes across disciplines at a public university. The intention was to obtain a group of young US adults with typical health literacy that was transitioning from parental households to more independent living at university. Students enrolled in health professions courses, genetics courses, or providing patient-care in a healthcare facility were excluded. Students raising children or who had lived in the United States less than ten years were excluded. The target group was chosen because transition from dependence on parents to relatively independent university life usually involves establishing relationships with new primary care or school-based clinicians. This period may be an ideal opportunity to teach young patients about the importance of family health history and to generate comprehensive and useful pedigrees.

Students were invited to participate in the study by means of a letter distributed in undergraduate classes across several disciplines. Because attendance was not checked for the study, the number of students receiving the recruitment letter in each class is unknown; however the letter was distributed to at least 400 students. Interested students provided contact information, and a member of the research team made contact and explained the study. Thirty students replied to the recruitment letter and 18 students kept appointments for interviews. When students could be re-contacted, the reason for no follow-through with the stated intention to enroll was conflicting demands. Students received a \$10 Starbuck's ${ }^{\mathrm{TM}}$ gift certificate as a thank you token, but were otherwise not reimbursed. It was our assumption that students who did participate were motivated, at least partially, by an interest in their personal health as the study was health related and offered essentially no benefits to the participant. Thus, this self-selected sample may have differed from other students in some respects, but we conjectured that this group had a baseline interest in family history and health at least the equal of other students.

\subsection{Protection of Human Subjects}

The study was approved by the Institutional Review Board of the target university and privately funded. The authors had no conflicts of interests to declare. Participants were informed of the purpose of the research and 
procedures involved, and each provided written consent. Interviews were private, and participants had the option to end the interview at any time. Participants were asked for permission to audiotape prior to the interviews.

\subsection{Data Collection}

Participants were interviewed by registered nurses (the authors) with training and experience in interview and active listening techniques. Interviews were guided by a semi-structured interview tool (available upon request from first author). The tool was an algorithm that led the interviewer through greeting, introduction, and explaining what a $\mathrm{FHH}$ was, questions regarding how the respondent learned facts about family members' health, and finally to questions regarding respondents' feelings about the importance of FHH in their own health. Probe questions were added during the 45 - 60 minutes interviews at interviewer discretion based on participant responses. Tapes were subsequently transcribed by personnel who were blind to the identity of the subjects and had no other role in the research process. Transcripts were transferred to NVivo-8 software, which was used for organizing memos; searching, organizing and recording codes; and counting text objects.

\subsection{Analysis}

Investigators applied thematic analysis to transcribed texts of conversations. Text analysis was performed using the constant comparative method originally described by Glaser and Straus [18] and further defined by Glaser [19-21]. Preliminary open and selective coding was performed by three members of the research team during multiple sessions.

Open coding resulted in classification of categories of behaviors or events. No concepts or categories were assumed a priori. Saturation (point at which no new codes were identified) occurred at case 14 but coding continued until all cases were coded. The open coding process was conducted systematically by reading each complete transcript, then identifying units of meaning, such as phrases and sentences, in each conversation. Meaning units were categorized into multiple thematic codes, which were compared and reduced. Final theoretical coding, integration, and interpretation were performed by all investigators jointly.

\section{RESULTS}

\subsection{Transmission of Family Health Information}

Young adults described two processes by which they obtained information about family health, which we labeled hanging around and trickling down (Figure 1). In

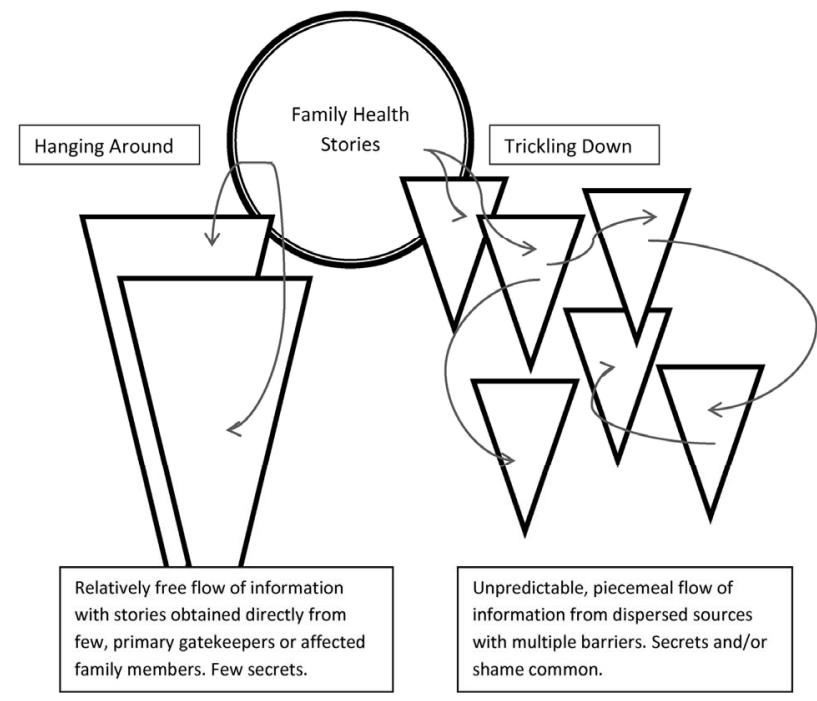

Figure 1. Models of family health information flow from family to children and young adults.

both cases FHH information was derived unintentionally from the background interactions that occur in every family. Background refers to verbal and non-verbal communication that occurs from moment to moment in every family and is observed by children who may or may not be the targets of communication. From the perspective of child observers, facts about health of family members tend to be buried within the family background noise. The major predictor of whether a respondent participated in hanging around rather than trickling down was physical proximity of family members. Participants who lived in close physical proximity to other family members described a process of hanging around in which they overheard stories or participated in informal, spontaneous conversations regarding illnesses (subject ID indicated in parentheses).

Well everybody that lives here [nearby] I know doesn't have health problems because I see them. (3)

I was just familiar with him [Grandfather] and then my grandmother; she just played a really big part of my life so I've always known her. I mean, she just talks day in and day out. You know, oh, this arthritis, and then my grandfather. I mean, we were close as a family growing up so we just kinda knew that he had a heart attack... (5)

And how did you find all that about your [relative]? I've overheard him talking to my mom about it and stuff. (4)

These individuals also learned about illnesses of family members through direct caregiving activities or by directly witnessing relatives' loss of function due to disease.

For instance, one participant learned of his father's epilepsy through exposure to seizures,

...he had always told me to reach for his wallet and put it in his mouth to keep him from biting his tongue 
off... and then get help. As I got older he would explain what it is, and some of the episodes he had, but ah other than that I don't know about too much. I mean I've looked up some things, but I mean it's just general knowledge. (12)

In this case the young adult reported that he had been exposed to his father's seizures for many years, but still believed he was poorly informed about epilepsy. The belief that the respondent was poorly informed about the medical facts related to family diseases was typical of most participants.

Other participants might recognize a family member's health problem when a dramatic event, such as a trip to the hospital, was observed. Hospital trips involving parents were reported as intensely distressing by most hanging around participants, even if they were not present,

They ruled it out [parent was having chest pain]. I mean, I don't know what, what exactly it was. I mean, I was at the school and then I came back home. I came home and he was like, I went to the hospital today. I'm like, and I didn't hear about this? Wow, thank you... it was quite frightening. (12)

When physical proximity was complemented by emotional closeness, the volume of information, if not the accuracy, was enhanced. In one case proximity was not spatial, but was cultivated intentionally by emotionally attached family members through regular telephone communication in which news about illnesses was shared. The father was the gatekeeper for health information from his family in another country, and he passed the information on to his child,

[grandfather doesn't talk directly to participant about his health problems]... Not his health problems, except for the war wounds. My dad will tell me. My dad will talk to him probably once a week or so and ask him about his week. He'll say I got this, this week or something. (18)

Young adults, who described more distant emotional relationships within families and less physical proximity, reported a process of trickling down in which information was received erratically through unpredictable channels from various family members. Information accuracy was more questionable and the volume of information was decreased in trickling down cases.

I think my grandfather is still alive, but I'm not sure. Do you know how old he is? I have no idea. How about your grandmother? No Not that I know of. Do you know anything about your grandmother? Is she dead or alive? I don't know anything about her. (15)

Participants who were involved in the trickling down process sometimes reported wishing they knew more about their family's health problems and recognized that the health problems of relatives could have implications for themselves. However, trickling down implied a lack of access to desired family information.

I wish I knew more about my family... like ... I'd like to know, um, more about it because when my sister had colon problems, I was getting a little scared and I was like, oh, I might have or get colon problems and so I was reading a lot about it and I wanted to know more... (14)

When gatekeepers in trickling down situations were recognized they sometimes acted as communication barriers rather than conduits, and hints were often dropped about family secrets.

So you knew more about your mom's background than he [father] did? Yes. I was definitely a friend to her. But it was kind of nice because I understood. And that was a hard thing when she passed away because no one in the family understands... anymore. She was the only one that knew. (4)

Do you know anything about [mother's] cancer? What type it was? No I don't. Do you feel comfortable asking her? Probably not. I don't know. I think it's a depressing topic. And when my brother got cancer you know she was feeling really down herself. So you might not ask her because it might make her depressed to talk about it? Yeah probably. (7)

Respondents who reported trickling down were more likely to report that they disliked family members or disapproved of the health-related behaviors of family members.

... I wanted to kind of move away from all that because they still drink all the time and so that's what made me move up here. (14)

Respondents who described physical and emotional closeness to family members, especially information gatekeepers, knew more about family members' health and seemed more interested in the subject. In either process, respondents described learning about health conditions of family members in a passive way. They rarely directly questioned affected family members or gatekeepers about family health events. Only one persistent participant described direct questioning of her family members about their health,

...they don't talk about anything back home, really. I have to dig it out of them. (14)

Direct observation of dramatic changes in family members as a result of illness was the most powerful cue for learning about family health history for all respondents. A respondent with a strong family history of melanoma described the contrast between the impact of seeing his grandmother whose face was disfigured as part of cancer treatment and the lessons presented at school.

I think that it made a profound effect to see directly what happens to your family cause it's not, it's not like reading about it in a book, I mean you're seeing it directly. In school they would always bring people in to 
talk to you and then show you videos and you'd read a book or you'd see a diagram or a picture and they'd tell you this is what'll happen but there's no connection to it, you can't relate to it. (1)

Other respondents described dramatic events, such as a mother who suddenly disappeared as a result of depression, a grandfather whose colon cancer resulted in making him the recipient of the family's direct caregiving, relatives whose alcoholism or abuse destroyed family relationships and family members who required hospitalizations or surgery. In such cases it was difficult for the respondent to minimize or normalize the illness and respondents had substantially more knowledge about the health history of such family members. Even visually observing a family member take pills was extraordinary enough to lead some respondents to learn about the family member's illness.

Patient probing by interviewers resulted in substantial enrichment of the historical data in every case. Most respondents offered very little information in the beginning of the interview, which usually included the occurrence of major impact illnesses, such as cancer. They did not report mental illnesses until prompted.

It was impossible to verify the accuracy of family health information, but respondents were queried regarding their understanding of illnesses they reported. Understanding of specific illnesses and treatments was usually superficial and often inaccurate, including cases in which the respondent had provided direct care to a family member with an illness or was emotionally close to the affected family member. For instance, one respondent commented on her brother's allergies and asthma:

The only thing he have is allergies and asthma... He gets these little scars on his arms and legs and that's with his allergies. When asked the cause of the scars the student replied, from drinking too much soda. (11)

And another respondent reported the reasons for her grandfather's medications:

...he's on Flomax, so that's because he drinks so much coffee during the day. (6)

Respondents' understanding of their own current or past health problems was sometimes unclear, as well. For instance the following comments reflected the extent of respondent knowledge about the conditions they mentioned having:

I don't know if it (asthma) can go away or if it did go away or if I just was dreaming that I had it. I don't have it now. (1)

I have a club foot and that's about it... my grandmother told me that there's a rod there... my leg probably got stuck somewhere. It was deformed. (11)

I kind of have a heart problem. (10)

\subsection{Information Sources}

Previous studies suggest that the accuracy of family histories depends on the informant [22-24]. Respondents in this study identified multiple informants who shared information about health conditions occurring in the family. The identity of the informant was influenced by family dynamics, the health conditions of family members, and physical or emotional closeness to the respondent. In one family, an aunt who was a healthcare professional educated the respondent and his siblings about the family health history. In another family, the father transmitted the limited information available because the mother was not emotionally available due to mental illness. In other families, grandparents, parents, siblings, aunts, and uncles passed family health information to the respondents in different situations.

How do you find out about people's health problems? Who knows most of the information? One of my aunt's that lives in [place]. She's always telling us what is going on. She calls my dad and he tells us. (2)

Often older family members would directly report their health problems in the context of instructions regarding what to do in cases of emergencies. In contrast to earlier research and anecdotal accounts of maternal or grandmotherly gatekeeping roles, family health information seemed to lodge unsystematically and partially with various family members. This contributed to the relatively inefficient "hanging around" or "trickling down" processes because, in most cases, no single individual assumed responsibility for collecting and transmitting family health information and no single individual had access to all pertinent information.

\subsection{How Young Adults Perceive Health}

Describing young adults' views of health was not a specific purpose of the study; however, respondents' view of health emerged quickly and was recognized as a recurring theme. The theme was coded and analyzed because it was thought to relate to the ways respondents viewed FHH. Over the entire sample, health meant being attractive, functioning physically and socially in an expected manner, and being successful. For instance a relative was perceived to be healthy because,

He's just the handsomest kid I ever seen. He's already taller than me, so he's healthy. (1)

For males and a few females, athletic talent implied health. Referring to personal good health, participants' comments were typical of the following,

I'm athletic. I'm tall. I've never had a weight problem. (18)

Some respondents expressed the awareness that personal health included social and emotional aspects, as well as physical aspects: 
I don't have any medical type conditions but since this is my first year down here I would say that socially... I'm not, "healthy" because I have not met a wholelot of people, so I don't feel really connected. And I think that's part of being healthy. (17)

Respondents shared the view that health was not the absence of disease. In fact, in most cases family members with chronic illnesses were described as normal if they functioned age appropriately. Age appropriate functioning was a highly valued characteristic and signified health. The presence of illness was considered unhealthy when it resulted in obvious physical abnormality or poor functioning. Thus a sister with hypothyroidism was healthy because her appearance and behavior were normal. Because the respondent did not perceive the sister as unhealthy, the information about the sister was not spontaneous, but elicited after asking about family members who take medications.

...my sister has a thyroid condition, but, I mean, I think it's pretty normal like there's nothing abnormal about it. She just has one of the thyroid you know hyper and hypo... (5)

A brother was healthy because he is "handsome and tall”. Although she was taking medications, a 79 year old grandmother was described as healthy because she did not have cancer.

The adjective, "healthy”, was applied to people only 4 times, although it was used often to describe diets and behaviors. The belief that if a person adheres to healthy behaviors he or she will avoid illness was expressed frequently. For instance, when asked how she considered her own health, a participant responded with a description of healthy behaviors,

Really good because I don't smoke, I mean I just turned 18 last year so I don't drink at all. I eat well because we don't eat a lot of processed food. (6)

The healthy behaviors mentioned by students included eating vegetables, getting exercise, limiting calories, and avoiding smoking and alcohol.

\subsection{Empowerment and Vulnerability}

All but two respondents described empowerment and/or a sense of vulnerability that resulted from their knowledge of FHH. Empowerment was expressed as the ability to respond to known risks by changing lifestyle. The intention to change behavior to avoid a negative health outcome conveyed feelings that the individual was vulnerable to the undesired outcomes.

...it seems like depression probably runs in the family with my mom and my sister and the high cholesterol does, so [knowing the history is useful] just so I would know that I am at high risk for high cholesterol so I should not be eating a lot of [food list]; and I am at risk for depres- sion so I would have to stop [behavior], but know what you're at risk for and counter that with your diet... (17)

I just know it [family health information] you know and I'm aware of it and I do think about it because I want to head off some of those things like the hypertension, so, yes, I do use it. (13)

Many participants discussed the influence of the FHH in terms of role models. For these participants, the FHH served as a cautionary tale in which characters modeled the consequences of their unhealthy past behaviors and the respondent learned from the example of the affected family member. For example, family members with skin cancer, diabetes, obesity, violent behavior, alcoholism, and depression were cited as demonstrating examples of unhealthy behaviors.

My [parent's] mom drinks a lot. She's a pretty heavy drinker. Does that bother you sometimes? Yeah, me and my grandma are really close but I feel like after her surgery, after all that happened she started drinking more than she normally did and it bothers my [parent] so much... (8)

I mean to learn both by good example and bad example and, if anything, at least I've seen that [disease] and it's made me aware of what it can do and it makes me very cautious and at times worried and I make very sure that I'm not in that situation... (12)

On the other hand, family members who ate diets perceived by the respondents as healthy, who exercised frequently, and who maintained their weight at an appropriate level were cited as good examples of health and healthy living.

[parents have] a really healthy living attitude, um, and my dad, you know, both my parents walk everyday and they try to stay fit, my mom is very healthy eater and my sister's a vegetarian. (5)

After my mom talked about the high cholesterol I actually went on the same diet that she's on. (17)

In summary, participants who believed family health history had an impact recognized the value of role modeling. They noted that poor health choices of other family members and the negative consequences of those choices motivated the young adult to espouse avoiding similar choices. Likewise, exposure to family members, especially parents, who made wise health choices, motivated the participant to espouse behaviors they believed to result in health. Most participants believed the FHH was valuable information with the potential to change their lives.

\section{LIMITATIONS}

Thematic analysis, regardless of specific method, is subjective and ultimately concerned with classifying content 
and interpreting meaning. Coding content is straightforward, but the correctness of the analysts' transfers of meaning intended by informants cannot be demonstrated. Some degree of interpretive trust is required by the reader [25]. To promote consistency, interviewers constructed the interview guide together and agreed on core questions that would be asked of every participant. Interviewers also reviewed transcripts together as transcripts were available, discussing not only the coding but also possible additional questions for subsequent interviews. Transforming codes into themes and interpreting their meaning was a joint undertaking. This qualitative exploration provides theoretical insights that can generate hypotheses for more traditional hypothesis testing.

\section{DISCUSSION}

The informal nature of the processes of transmitting family health information and the relatively passive roles of the young adult who is a child in the family were common to both hanging around and trickling down processes. From an emotional perspective, young adults in this sample were still adolescents. Their frequent lack of interest in the illnesses of other family members is consistent with the egocentric character of their developmental stage. This may explain the lack of curiosity of some participants about family health matters and the lack of direct question-asking on the part of most respondents, as well as the lack of accurate information about illnesses they described.

Respondents did not intentionally seek information about family health problems. What they knew was often cued by episodes that affected them directly or by overheard conversations. Dramatic episodes, such as a parent entering a psychiatric hospital, made an impact, but the family response to health crises determined how the participant understood health problems. Family dynamics played a critical role in the acquisition of accurate family health data. Fragmented and emotionally conflicted relationships within the family resulted in fragmented and inaccurate or incomplete family health histories.

Many important illnesses do not result in dramatic crises and are not noticed by children. They are chronic conditions that are controlled with medication and thus "invisible" to family members unless the patient chooses to disclose the situation. If young adults perceive health as attractiveness and normal functioning, the existence of chronic, albeit controlled, illness may be completely missed or minimized in importance.

Adolescents are frequently exposed to intentional conversations about the "facts of life", regarding sexually transmitted disease, reproduction, and drugs. In contrast, the FHH is a collage of bits and pieces of information that is collected throughout childhood. It is not in- tentionally organized or explained when individuals are old enough to benefit from the effort. Because an accurate family health history still offers the best data for calculating risk of complex disease and many monogenic disorders, it is important that clinicians encourage patients to obtain this information. Young adults attending university are typically in the process of transitioning from the care of pediatricians or local family physicians into relationships with new healthcare providers, thus this stage is an opportune time for families to construct an organized family health history with them.

\section{CONCLUSIONS}

FHH information provided by young adult undergraduate students is characterized by inaccuracies related to inadequate information and lack of understanding of information that is available regardless of the model of information transmission involved. Nurses should critically evaluate family health histories from adult students and other young adults actively transitioning from the parental home. The transition period from high school and home to university and independent living is an ideal time to assist young adults with constructing a complete and accurate FHH. During this stage of development the concept of health may be tightly linked to self-concept and the desire to be attractive, so students may be eager to respond to learning ways to collect and organize family health history information. In addition, many students are still under the care of pediatricians who may have some FHH recorded. Ways of sharing this information with young adult patients transitioning to adult caregivers need to be explored.

The length of time devoted to the interviews in this research would be unrealistic for clinical practice, and yet young adults required patient listening and probing questions in order to deliver useful information. For young university students, a self-report disease checklist, typical of FHH inventories used in primary care practices, will likely miss much relevant information. A well-structured interview conducted in an unrushed manner by an individual with enough biomedical training to understand the implications of respondents' descriptions may be a viable solution. Other creative solutions might include group interventions to raise the awareness of young adults regarding the importance of $\mathrm{FHH}$ and to help them learn to collect and organize information from family members or paper "graduation" packets containing personal and family health histories that are prepared for and reviewed with young adults moving from the care of pediatricians or local family physicians. Nurses in college health services, primary care pediatrics, and public health are well positioned to implement innovative strategies for family history collection that assist individuals transitioning from home to university or college. 


\section{ACKNOWLEDGEMENTS}

The authors wish to acknowledge the assistance of the Center for Nursing Scholarship and Technology at the University of Texas at Arlington for assistance with interview transcription. The authors further wish to thank Justina Amalu, RN MSN, Ingrid Kelley, LVN, and Crystal Morris for help with recruitment activities in this study.

\section{REFERENCES}

[1] Berg, A.O., Baird, M.A., Botkin, J.R., Driscoll, D.A., Fishman, P.A., Guarino, P.D., Hiatt, R.A., Jarvik, G.P., Millon-Underwood, S., Morgan, T.M., Mulvihill, J.J., Pollin, T.I., Schimmel, S.R., Stefanek, M.E., Vollmer, W.M. and Williams, J.K. (2009) National Institutes of Health state-of-the-science conference statement: Family history and improving health. Annals of Internal Medicine, 151, 872-877.

[2] Centers for Disease Control and Prevention (2010) Gather and share your family health history. http://www.cdc.gov/Features/FamilyHealthHistory/

[3] Trotter, T.L. and Martin, H.M. (2007) Family history in pediatric primary care. Pediatrics, 120, S60-S65. doi:10.1542/peds.2007-1010D

[4] Cannon, E.A., Schoppe-Sullivan, S.J., Mangelsdorf, S.C., Brown, G.L. and Sokolowski, M.S. (2008) Parent characteristics as antecedents of maternal gatekeeping and fathering behavior. Family Process, 47, 501-519. doi:10.1111/j.1545-5300.2008.00268.x

[5] McKee, M.D., O’Sullivan, L.F. and Weber, C.M. (2006) Perspectives on confidential care for adolescent girls. Annals of Family Medicine, 4, 519-526. doi:10.1370/afm.601

[6] Schoppe-Sullivan, S.J., Brown, G.L., Cannon, E.A., Mangelsdorf, S.C. and Sokolowski, M.S. (2008) Maternal gatekeeping, coparenting quality, and fathering behavior in families with infants. Journal of Family Psychology, 22, 389-398. doi:10.1037/0893-3200.22.3.389

[7] Roberto, K.A. and Stroes, J. (1992) Grandchildren and grandparents: Roles, influences, and relationships. International Journal of Aging and Human Development, 34, 227-239. doi:10.2190/8CW7-91WF-E5QC-5UFN

[8] Robertson, J.F. (1977) Grandmotherhood: A study of role conceptions. Journal of Marriage and the Family, 39, 165-174. doi:10.2307/351072

[9] Waldrop, D.P., Weber, J.A., Herald, S.L., Pruett, J., Cooper, K. and Juozapavicius, K. (1999) Wisdom and life experience: How grandfathers mentor their grandchildren. Journal of Aging and Identity, 4, 33-46. doi:10.1023/A:1022834825849

[10] Weber, J.A. and Absher, A.G. (2003) Grandparents and grandchildren: A “memory box" course assignment. Gerontology and Geriatric Education, 24, 75-86. doi:10.1300/J021v24n01_06
[11] Erickson, E. (1974) Dimensions of a new identity. Norton, New York.

[12] Kivnick, H.Q. (1982) Grandparenthood: An overview of meaning and mental health. The Gerontologist, 22, 59-66. doi:10.1093/geront/22.1.59

[13] McAdams, D.P., de St. Aubin, E. and Logan, R.L. (1993) Generativity among young, midlife, and older adults. Psychology of Aging, 8, 221-230. doi:10.1037/0882-7974.8.2.221

[14] Fiese, B.H., Hooker, K.A., Kotary, L. and Schwagler, J. (1995) Rimmer M. Family stories in the early stages of parenthood. Journal of Marriage and the Family, 57, 763-770. doi:10.2307/353930

[15] Martin, P., Hagestad, G.O. and Diedrick, P. (1988) Family stories: Events (temporarily) remembered. Journal of Marriage and the Family, 50, 533-541. doi:10.2307/352018

[16] Maturana, H.R. (1978) Biology of language: The epistemology of reality. In: Miller, G.A. and Lenneberg, E. Eds., Psychology and Biology of Language and Thought. Academic Press, New York.

[17] Gerben, K. (1985) The social constructivist movement in modern psychology. American Psychology, 40, 266-275. doi:10.1037/0003-066X.40.3.266

[18] Glaser, B. and Strauss, A. (1967) The discovery of grounded theory: Strategies for qualitative research. Aldine, Chicago.

[19] Glaser, B. (1978) Theoretical sensitivity: Advances in the methodology of grounded theory. Sociology Press, Mill Valley.

[20] Glaser, B. (1992) Basics of grounded theory analysis. Sociology Press, Mill Valley.

[21] Glaser, B. (1998) Doing grounded theory: Issues and discussions. Sociology Press, Mill Valley.

[22] Kendler, K.S., Silberg, J.L., Neale, M.C., Kessler, R.C., Heath, A.C. and Eaves, L.J. (1991) The family history method: Whose psychiatric history is measured? American Journal of Psychiatry, 148, 1501-1504.

[23] Romitti, P.A., Burns, T.L. and Murray, J.C. (1997) Maternal interview reports of family history of birth defects: Evaluation from a population-based case-control study of orofacial clefts. American Journal of Medical Genetics, 72, 422-429.

doi:10.1002/(SICI)1096-8628(19971112)72:4<422::AIDAJMG10>3.0.CO;2-T

[24] Smith, E.M., Przybeck, T.R., Bradford, S.E., Gogineni, A. and Spitznagel E.L. (1994) Adult offspring of alcoholic women as family history informants. Alcoholism Clinical and Experimental Research, 18, 1354-1360. doi:10.1111/j.1530-0277.1994.tb01436.x

[25] Schutz, A. (1962) Collected papers I: The problem of Social reality, part I. Martinus-Nijhoff, The Hague, Amsterdam. 